\title{
Study on Surgical Management of Humeral Shaft Fractures by Various Modalities
}

\author{
Dr. Saini Thirupathi ${ }^{1}$, Dr. Mamidi Anil Kumar ${ }^{2 *}$
}

${ }^{1}$ Assistant Professor, ${ }^{2}$ Assistant Professor, Department of Orthopedics, Prathima Institute of medical sciences, Nagnoor, Karimnagar, Telangana India

DOI: $10.36347 /$ sjams.2020.v08i12.017

| Received: 29.11.2020 | Accepted: 12.12.2020 | Published: 14.12.2020

*Corresponding author: Dr. Mamidi Anil Kumar

Abstract

Original Research Article

Introduction: Fractures of humeral shaft account for approximately 3\% of all fractures. Most fractures may heal conservatively by hanging casts [1], although a small but consistent number will require surgery for optimal outcome. Aim: To assess the results of humeral shaft fractures managed by various surgical modalities. Materials and methods: This is a prospective study of 40 cases of fracture shaft of humerus admitted in department of orthopaedics, Prathima Institute of medical sciences, Nagnoor, Karimnagar, and Telangana between October 2018 to September 2020. Cases were taken according to inclusion and exclusion criteria. Various modalities used were : Broad or narrow 4.5mm DCP, LCP, extra articular distal humeral long plates, TENS, rush nails, Enders nails, inter locking nail humerus, Ilizarov fixator, External fixation for additional stability in case of TENS and rush nails and also for temporary immobilization in case of infected non-union. Case follow up done up to 2yrs. Results: In our series of 40 cases, there were 23 males and 17 females, with average age of 44 yrs. 29(72\%) cases were admitted due to road traffic accident and with slight predominance of left side. Out of 40 cases, $4(10 \%)$ were proximal third, 32(80\%) were middle third and $4(10 \%)$ were distal third. Transverse or short oblique fractures were most common i.e., 27(67\%) patients. 4(10\%) cases were having associated injuries. The fractures united in $28(70 \%)$ patients with $6(15 \%)$ cases going for non-union. There was $6(15 \%)$ case of delayed union which united after 6 months. Good or full range of mobility of shoulder and elbow joints was present in $30(75 \%)$ patients with $1(2.5 \%)$ patients having stiffness of elbow. Conclusion: Surgical management of the humerus shaft fractures with various methods achieves variable union rates. Each implant has its failure rates whatever may be the fracture type. Union rates not only purely depends on implant but also on age, bone quality, infection, activity, fixation stability and many other at to known factors.

Key words: Humerus, fracture management, union.

Copyright $\odot 2020$ The Author(s): This is an open-access article distributed under the terms of the Creative Commons Attribution 4.0 International License (CC BY-NC 4.0) which permits unrestricted use, distribution, and reproduction in any medium for non-commercial use provided the original author and source are credited.

\section{INTRODUCTION}

Fractures of Humeral shaft account for approximately $3 \%$ of all fractures. Most fractures may heal conservatively by hanging casts, although a small but consistent number will require surgery for optimal outcome. The aim of this study is to assess the results of humeral shaft fractures by various modalities.

\section{Patients And Methods}

This is a prospective study of 40 cases of fracture shaft humerus admitted in department of orthopaedics, Prathima Institute of medical sciences, Nagnoor, Karimnagar, and Telangana between October 2018 to September 2020. Data collected from patient records and while follow up of cases. Pre-Op Evaluation was done by History, Examination, Standard radiographs of the humerus, i.e., anteroposterior and lateral views including elbow and shoulder were obtained. The limb was immobilized in a U-slab with sling. Routine investigations were done and informed consent taken. Physician, pulmonologist and cardiac fitness was obtained in each case.

\section{Inclusion criteria}

1. Patients of all age groups who are fit for surgery.

2. Patients who are given consent for research study.

3. Both fresh and old untreated fractures.

4. All cases with or without pre-operative radial nerve palsy

\section{Exclusion criteria}

1. All open fractures.

2. All pathological fractures.

3. All paediatric fractures. 


\section{Surgical procedure}

In each case depending on the fracture location we opted for anterolateral or posterior approach in case of open reduction. In closed reduction by nailing we used greater tuberosity medial entry point and for TENS, rush nails, ender nails we used distal metaphyseal area entry points.

\section{Implants used are}

1. Broad or narrow $4.5 \mathrm{~mm} \mathrm{DCP(16} \mathrm{cases})$, LCP (8 cases)

2. Extra articular distal humeral long plates (4 cases)

3. TENS nails of different diameters (3 cases)

4. Rush nails of different diameter (2 cases).

5. Ilizarov fixator (2 cases).

6. Enders nails( 2 cases)

7. Inter locking nail humerus( 3 cases).

8. External fixation for additional stability in case of TENS and rush nails and also for temporary immobilization in case of infected non-union.

Standard surgical procedure was followed.

\section{Follow Up}

Range of motion exercises of shoulder and elbow were started either immediate or during follow up depending on stability of fixation. All the patients were followed up at 6 week interval till fracture union and once in 6 months till the completion of study.

\section{RESULTS}

Total no. of patients was 40. Mean age of patients was 44 years (range: 18-70yrs). 23 patients were males and 17 were females. Left side was affected in 23patients (57\%) and right side was affected in 17 pts (43\%). Most common mode of injury was road traffic accidents in 29 patients $(72 \%)$, fall in bathroom in 7 patients(17\%), accident at work place in 4 patients $(10 \%) .4(10 \%)$ of the 40patients have associated injuries. Majority of the fractures were in the middle third (32in number i.e. $80 \%$ ).

Fracture Pattern Transverse or short oblique in 27 patients $(67 \%)$, Communited in 4 patients $(10 \%)$, spiral in 2 patients $(5 \%) \& 2$ segmental fractures (5) long oblique in 5 cases (12). General anaesthesia given in 10 and brachial block was given for 30 cases. The Anterolateral approach of Henry was used in 20 cases. Posterior approach was used in 8 cases. Tourniquet was not used in any of our cases, as it comes in the way of surgery so. The follow- up ranged from 6months to 24 months.

Duration of fracture Union in $28(70 \%)$ patients in less than 6 months, delayed union in $6(15 \%)$ patient, non- union in $6(15 \%)$. Range of Mobility (ROM) of the Shoulder and Elbow Joints 30(75\%) pts recovered full ROM of shoulder and elbow joint. 4 (10\%) patients recovered good ROM (within 10-15\% of full range). 3(7.5\%) patients had poor ROM, of these, 1 (2.5\%) patient had a paraplegic limb, $1(2.5 \%)$ patient had an elbow stiffness. The American Shoulder and Elbow Surgeons (ASES) shoulder score [2] is for 13 activities of daily living requiring full shoulder and elbow movement. The maximum possible score is 52 points. The average ASES score obtained was 45 . Complications in our study are shown in Table. Results according to Romen et al. scoring [3]: Excellent results in $24(60 \%)$ patients, Good results in $12(30 \%)$ patients, and Poor results in 4(10\%) patients. See Figures 1-4.

\section{Complications}

Complications are listed in Table 1

Table-1: Complications

\begin{tabular}{|l|l|l|}
\hline complications & No of patients & $\%$ \\
\hline Radial nerve palsy & $\begin{array}{l}3 \text { had preoperative palsy } \\
(2 \text { recovered by the end of 6months, } \\
1 \text { is re-explored), 2 post-operative palsies (recovered in } \\
4 \text { moths) }\end{array}$ & $\begin{array}{l}7.5 \\
5\end{array}$ \\
\hline Elbow stiffness & 1 & 2.5 \\
\hline Infected nonunion (needed re do surgeries) & 6 & 15 \\
\hline Superficial wound infections (needed debridement) & 4 & 10 \\
\hline Delayed union (needed teriparatide) & 6 & 15 \\
\hline Vascular compromise (re explored) & 1 & 2.5 \\
\hline Implant removals & $3(2$ impingements,1infected) & 7.5 \\
\hline
\end{tabular}




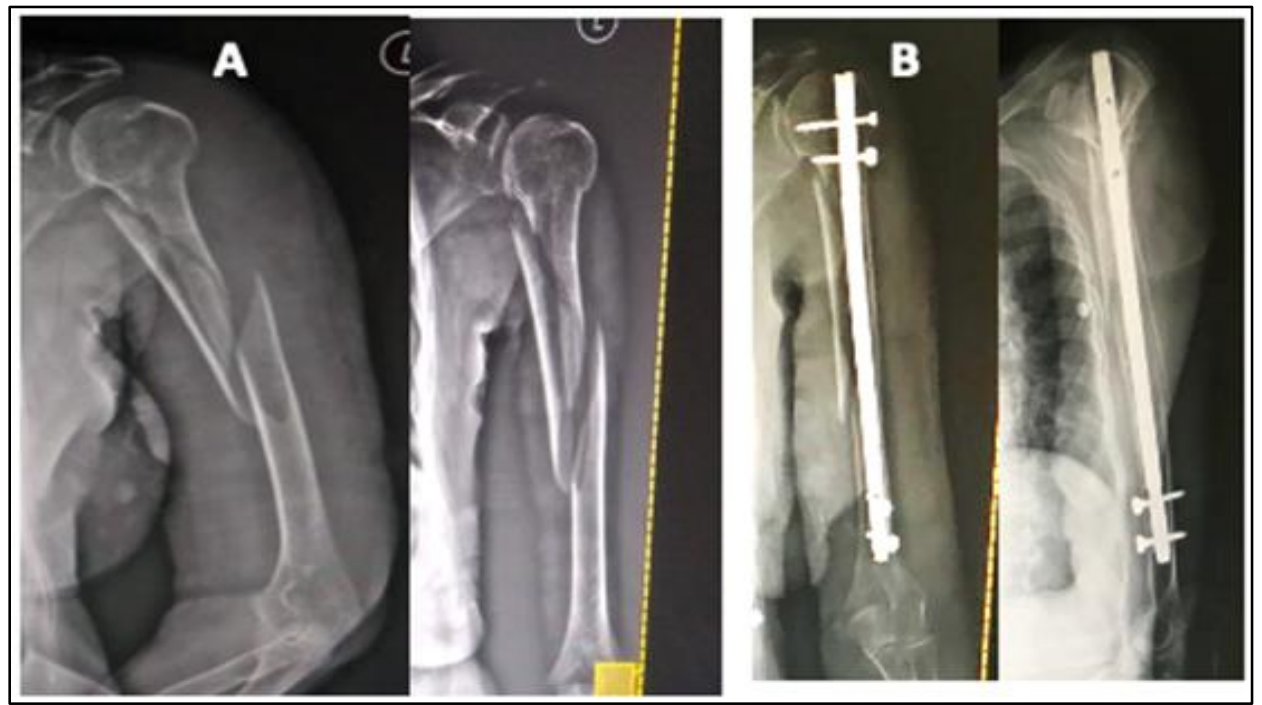

Fig-1: A) pre-operative radiograph B) post-operative radiograph showing intramedullary interlocking nail

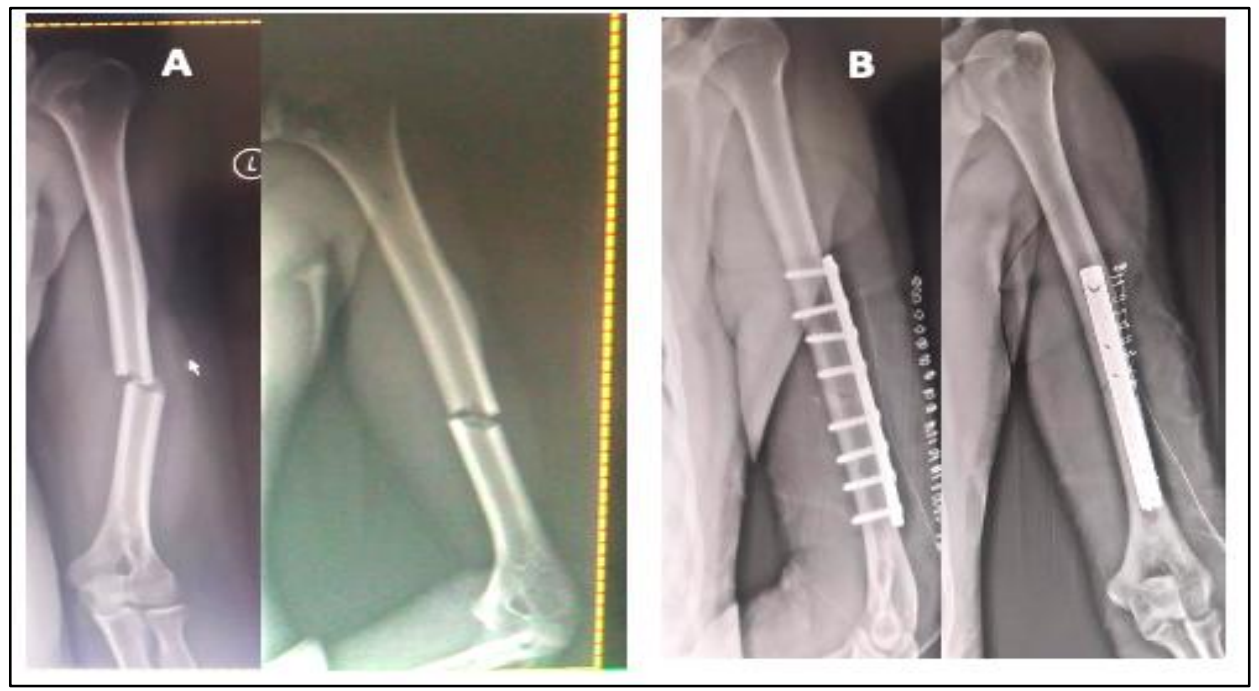

Fig-2: A) pre-operative radiograph B) post-operative radiograph showing locking compression plate
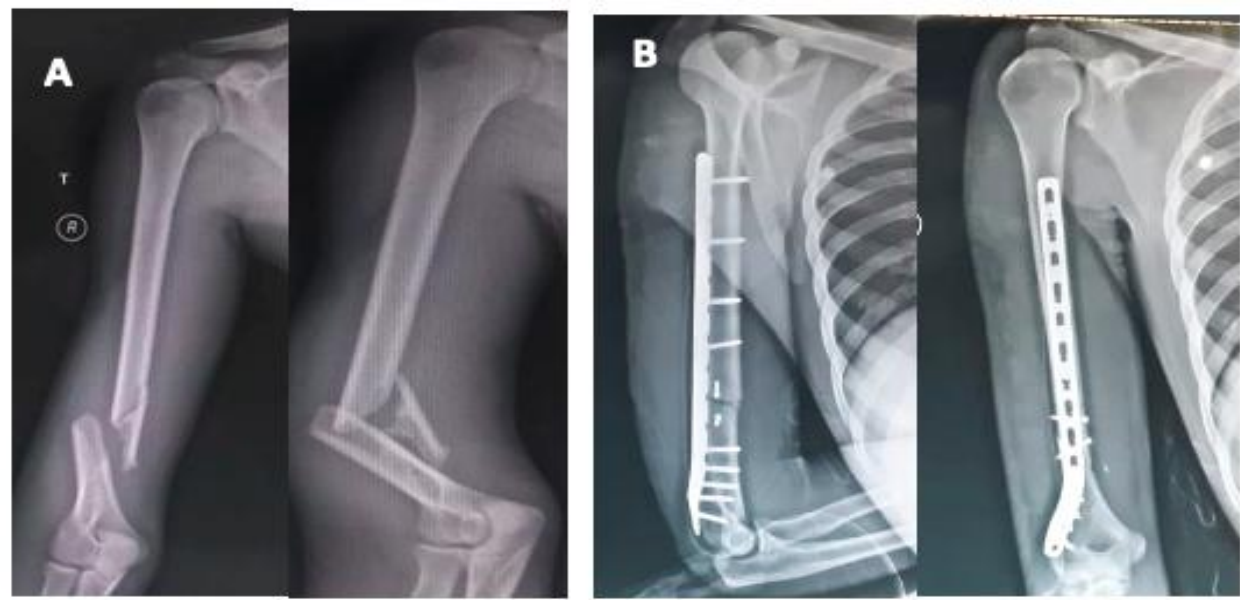

Fig-3: A) pre-operative radiograph B) post-operative radiograph showing extra articular distal humerus plate 


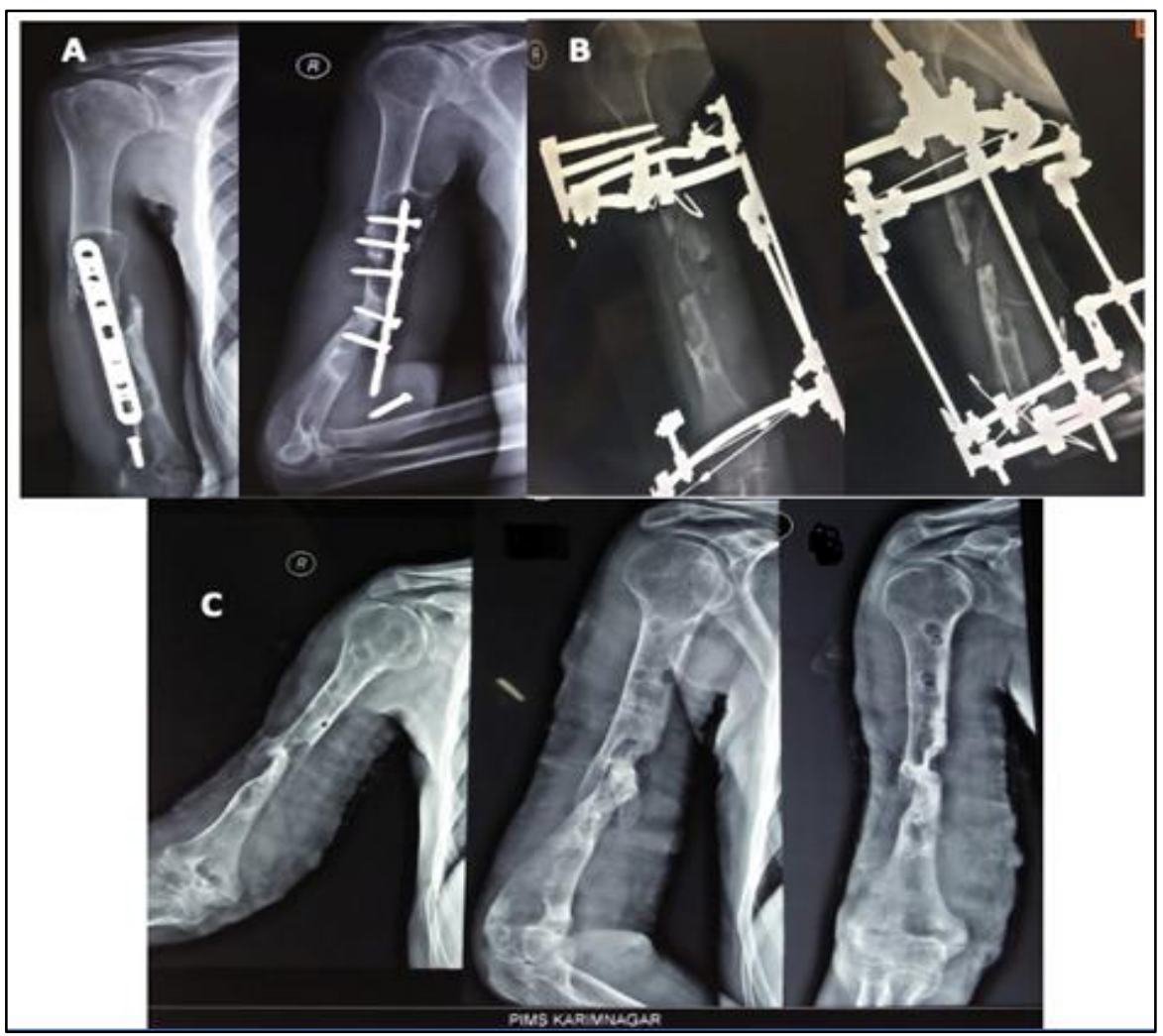

Fig-4: A) pre-operative radiograph with previous implant insitu B) post-operative radiograph showing Ilizarov fixator C) followup radiograph showing union

\section{DiSCUSSION}

Open reduction with plate fixation usually ensures a high likelihood of anatomic reduction, radial nerve exploration and ideal in patients with narrow medullary canal. Disadvantages of plating are extensive dissection with greater disruption of the soft tissue envelope, risk of infection, potential injury to the radial nerve (broad dcp) $(5 \%)$, poor fixation in osteoporotic bone with DCP and the possible need for plate removal at a later date. According to various studies non-union rate ranges from $1-9 \%$ with plating. Results of other studies are compared with our study in Table 2 .

Table-2: comparison with other studies

\begin{tabular}{|l|l|l|l|}
\hline study & No of patients & Implants & Excellent to good results \\
\hline Heim D et al. [4] & 127 & DCP & $87.3 \%$ \\
\hline Tingstad E M et al. [5] & 83 & AO Platin g & $94 \%$ \\
\hline McCormack RG et al. [6] & 44 & $\begin{array}{l}\text { DCP \& Intramedullary nail } \\
\text { fixation }\end{array}$ & $95.7 \%$ \\
\hline Present study & 40 & Various methods & $90 \%$ \\
\hline
\end{tabular}

In our study the results are all combined because we choose all implant types which are available at present market. Nonunion of $15 \%$ is significant in a small sample of 40 cases which is compared with already published articles table 2 from the research the observations for nonunion is

1. Early weight bearing in 1 case of inter locking humerus

2. Deep infection in 6 cases of plating by either LCP of DCP

3. Poor stability of fixation in case of using enders, rush nails and TENS which needed augmentation by external fixator in 2 cases

4. Patient factors like osteoporosis, diabetes, paralyzed limb, high demand activity
5. Surgeon factors like failure of dynamization while fixing, improper working length, wrong implant choice

6. Injury factors like segmental fractures, ipsilateral associated injuries.

Radial nerve palsy observed pre operatively in 3 cases, which explored at the time of surgery, 2 recovered well but in 1 case it needed re exploration at later time. Post operatively palsy seen in 2 cases which recovered fully in 4months of follow up. The reasons for palsy by our observation is using broad dcp and placing plate too posteriorly in one case, and in another case because of placing retractors over the nerve unknowingly while plate fixation causing compression in all our cases if nerve is exposed we used depomedrol 
[7] 40mg vial local infiltration prophylactically, and also we used dynamic cock up splint to prevent contractures in case of all palsy.

\section{Conclusions}

1) Rigid fixation of fracture shaft humerus obtained using DCP/ LCP or extra articular plate but it requires extensive exposure of fracture site and also disturbing the biology of fracture, and having wound healing problems. But having the advantage of exploring the radial nerve in case of entrapment.

2) Flexible nail fixation using retrograde technique requires very minimal soft tissue dissection and as it is a closed technique, the biology of fracture is also not disturbed but the rotational stability is at compromise.

3) Interlocking intramedullary nail gives stable internal fixation [8] but has its own disadvantage of rotator cuff problem when done by antegrade technique and delay in fracture union and needs removal of implant.

4) Ilizarov fixator for humerus is challenging, which needs expertise and high chance of neurovascular compromise [9] post operatively.

5) Surgical management of the humerus fractures with various implants achieves variable union rates. Each implant has its failure rates whatever may be the fracture type.

6) Union rates not only purely depends on implant type but also on age, bone quality, infection, activity, fixation stability, comorbid conditions like diabetes and many other unknown factors at to be known [10].

7) Merits of our study are we used all types of implants available for fixing shaft humerus in the present market, and studied complications of each implant individually.

8) Demerits of our study are, we used small sample size, and we combined external fixation modalities with internal fixation modalities even though two are having different complications related to wound. We included fresh fractures along with old untreated fractures and redo surgeries after failing initial surgery which might be the reason for bad results in some aspects.

\section{REFERENCES}

1. McKee MD. Fractures of The Shaft of The Humerus Rockwood \& Green's Fractures in Adults, 6th Edition, Bucholz, Robert W.; Heckman, James D.; Court-Brown, Charles M. Lippincott. 2006, 1118-1159

2. Brinker MR, O'Connor DP. The incidence of fractures and dislocations referred for orthopaedic services in a capitated population. J Bone Joint Surg Am. 2004; 86:290-297.

3. Wilson JN. Watson-Jones. Fractures and Joint Injuries, 6th ed. B.I. Churchill Livingstone PVT Ltd. New Delhi. 2002.

4. Colton CL, Fernandez A. Dell'Oca, Holz U, Kellam JF, Ochsner PE. AO Principles of Fracture Management: AO Publishers. 2000.

5. Klenerman L. Fractures of the shaft humerus. J Bone Joint Surg Br. 1966; 48:105-111.

6. Matthew W Lawless. Midshaft Humeral Fractures. eMedicine. 2004 July.

7. RF Hall, Pankovich AM. Ender nailing of acute fractures of the humerus. A study of closed fixation by intramedullary nails without reaming. J Bone Joint Surg Am. 1987; 69:558-567.

8. Zatti, Giovanni, Teli, Marco, Ferrario, Andrea, Cherubino Paolo. Treatment closed humeral shaft fractures with intramedullary elastic nails.

9. Andrew H. Crenshaw JR, Edward A Perez. Fractures of the shoulder, arm, and forearm. In: Campbells operative orthopaedics. 11th Edn. S. Terry \& James H. Beaty. 2008; 3(54):3395.

10. Michael D McKee, Sune Larsson. Humeral shaft fractures. In: Rockwood and Green's fractures in adults. 7th Edn. 2010; 1:34:1018. 